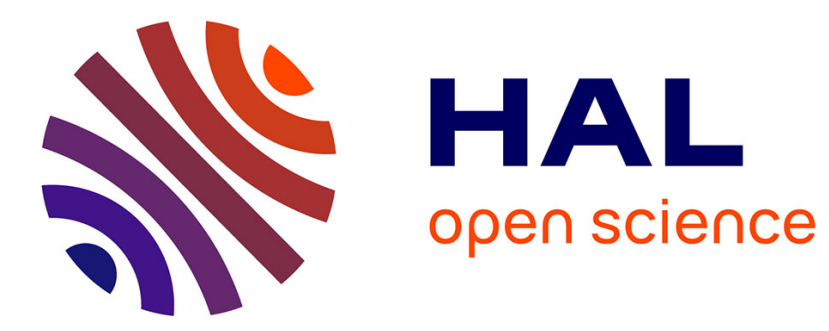

\title{
High-throughput measurements of bone morphogenetic protein/bone morphogenetic protein receptor interactions using biolayer interferometry
}

Valia Khodr, Paul Machillot, Elisa Migliorini, Jean-Baptiste Reiser, Catherine Picart

\section{To cite this version:}

Valia Khodr, Paul Machillot, Elisa Migliorini, Jean-Baptiste Reiser, Catherine Picart. Highthroughput measurements of bone morphogenetic protein/bone morphogenetic protein receptor interactions using biolayer interferometry. Biointerphases, 2021, 16, pp.031001. 10.1116/6.0000926 . hal-03266642

\section{HAL Id: hal-03266642 \\ https://hal.univ-grenoble-alpes.fr/hal-03266642}

Submitted on 22 Jun 2021

HAL is a multi-disciplinary open access archive for the deposit and dissemination of scientific research documents, whether they are published or not. The documents may come from teaching and research institutions in France or abroad, or from public or private research centers.
L'archive ouverte pluridisciplinaire HAL, est destinée au dépôt et à la diffusion de documents scientifiques de niveau recherche, publiés ou non, émanant des établissements d'enseignement et de recherche français ou étrangers, des laboratoires publics ou privés. 


\section{High-throughput measurements of bone morphogenetic protein/bone morphogenetic protein receptor interactions using biolayer interferometry}

Cite as: Biointerphases 16, 031001 (2021); https://doi.org/10.1116/6.0000926

Submitted: 13 January 2021. Accepted: 11 May 2021. Published Online: 08 June 2021

(iD) Valia Khodr, (D) Paul Machillot, (D) Elisa Migliorini, (D) Jean-Baptiste Reiser, and (iD) Catherine Picart
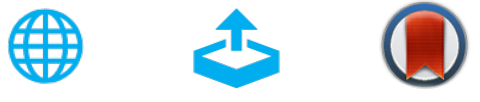

\section{ARTICLES YOU MAY BE INTERESTED IN}

Fréedericksz transition on air

American Journal of Physics 89, 603 (2021); https://doi.org/10.1119/10.0003350

Locally active memristor based oscillators: The dynamic route from period to chaos and hyperchaos

Chaos: An Interdisciplinary Journal of Nonlinear Science 31, 063114 (2021); https:// doi.org/10.1063/5.0048526

Quantum simulation and computing with Rydberg-interacting qubits

AVS Quantum Science 3, 023501 (2021); https://doi.org/10.1116/5.0036562

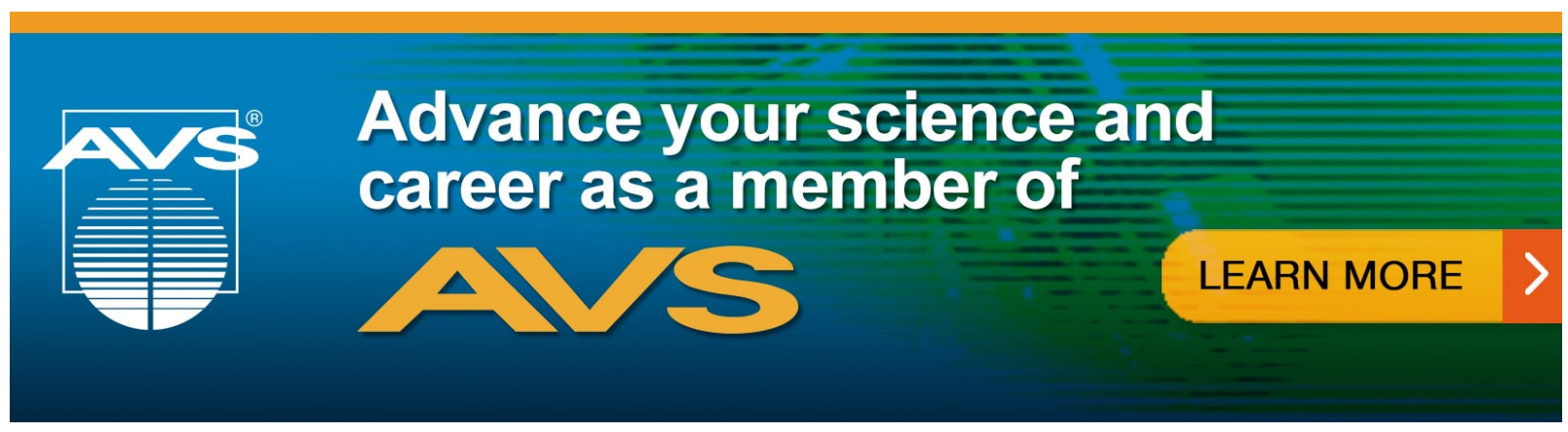




\title{
High-throughput measurements of bone morphogenetic protein/bone morphogenetic protein receptor interactions using biolayer interferometry
}

Cite as: Biointerphases 16, 031001 (2021); doi: 10.1116/6.0000926

Submitted: 13 January 2021 Accepted: 11 May 2021 .

Published Online: 8 June 2021

Valia Khodr, ${ }^{1,2}$ (D) Paul Machillot, ${ }^{1,2}$ (D) Elisa Migliorini, ${ }^{1,2}$ (D) Jean-Baptiste Reiser, ${ }^{3}$ (D) and Catherine Picart ${ }^{1,2, a)}$ (D)

\section{AFFILIATIONS}

${ }^{1}$ Interdisciplinary Research Institute of Grenoble (IRIG), ERL BRM 5000 (CNRS/UGA/CEA), CEA Grenoble, 17 rue des Martyrs, 38054 Grenoble Cedex, France

${ }^{2}$ CNRS, Grenoble Institute of Technology, LMGP, UMR 5628, 3 Parvis Louis Néel, 38016 Grenoble, France

${ }^{3}$ Institut de Biologie Structurale, UMR 5075, Univ. Grenoble Alpes, CEA, CNRS, IBS, F-38000 Grenoble, France

\begin{abstract}
${ }^{a}$ Author to whom correspondence should be addressed: catherine.picart@cea.fr
ABSTRACT

Bone morphogenetic proteins (BMPs) are an important family of growth factors playing a role in a large number of physiological and pathological processes, including bone homeostasis, tissue regeneration, and cancers. In vivo, BMPs bind successively to both BMP receptors (BMPRs) of type I and type II, and a promiscuity has been reported. In this study, we used biolayer interferometry to perform parallel real-time biosensing and to deduce the kinetic parameters $\left(\mathrm{k}_{\mathrm{a}}, \mathrm{k}_{\mathrm{d}}\right)$ and the equilibrium constant $\left(\mathrm{K}_{\mathrm{D}}\right)$ for a large range of BMP/BMPR combinations in similar experimental conditions. We selected four members of the BMP family (BMP-2, 4, 7, 9) known for their physiological relevance and studied their interactions with five type-I BMP receptors (ALK1, 2, 3, 5, 6) and three type-II BMP receptors (BMPR-II, ACTR-IIA, ACTR-IIB). We reveal that BMP-2 and BMP-4 behave differently, especially regarding their kinetic interactions and affinities with the type-II BMPR. We found that BMP-7 has a higher affinity for the type-II BMPR receptor ACTR-IIA and a tenfold lower affinity with the type-I receptors. While BMP-9 has a high and similar affinity for all type-II receptors, it can interact with ALK5 and ALK2, in addition to ALK1. Interestingly, we also found that all BMPs can interact with ALK5. The interaction between BMPs and both type-I and type-II receptors in a ternary complex did not reveal further cooperativity. Our work provides a synthetic view of the interactions of these BMPs with their receptors and paves the way for future studies on their cell-type and receptor specific signaling pathways.
\end{abstract}

Published under an exclusive license by the AVS. https://doi.org/10.1116/6.0000926

\section{INTRODUCTION}

Bone morphogenetic proteins (BMPs) are members of the transforming growth factor- $\beta$ (TGF $\beta$ ) superfamily that have been widely studied in view of the numerous physiological and pathological roles, ${ }^{1,2}$ including embryogenesis, development, bone homeostasis and regeneration, and cancers. ${ }^{3}$ The BMP family comprises more than 15 different ligands in humans, which have been grouped into four different subfamilies depending on their functions: BMP-2/4, BMP-5/6/7/8, BMP-9/10, and GDF5-6-7. ${ }^{3-6}$

Among these BMPs, BMP-2 is known for its role in morphogenesis, bone regeneration, and musculoskeletal disorders. ${ }^{7,8}$
In addition, BMP-4 plays a part in hematopoiesis and leukemia while BMP-7 is involved in inflammation and glucose homeostasis. ${ }^{10}$ BMP-9 and 10 have a major role in cardiovascular disease and anemia. ${ }^{11}$ Furthermore, BMPs have also been reported to have an increasing role in cancer. ${ }^{12}$

BMPs are active in their dimeric form and interact at the cell membrane with two subtypes of specific receptors [BMP receptor (BMPR)]: type-I and type-II BMPRs. ${ }^{2,4,5,13}$ Seven different type-I receptors (ALK1-ALK7) and five different type-II receptors (BMPR-II, ACTR-IIA, ACTR-IIB, TGFßR-II, and AMHR-II) are reported. BMPR-II, ACTR-IIA, and ACTR-IIB are associated with 
the binding of all BMPs, while TGF $\beta$ R-II and AMHR-II are reported to be specific of TGF $\beta$ ligands and anti-Müllerian hormone, respectively, but not BMPs. BMPs have been reported to mostly bind to four receptors: ${ }^{3}$ ALK1, ALK2 (also named ACTR-IA), ALK3 (also named BMPR-IA), and ALK6 (also named BMPR-IB). Each of these receptors has important physiopathological roles. For instance, for the type-I BMPRs, ALK1 is the predominant receptor in endothelial cells and is involved in cardiovascular diseases. ${ }^{11}$ ALK2 is an important receptor for bone homeostasis as a mutation in the ALK2 receptor is involved in a rare skeletal disorder named fibrodysplasia ossificans progressiva (FOP) and in a rare pediatric glioblastoma named diffuse intrinsic pontine glioblastoma. ${ }^{14}$ ALK3 plays a major role in several cancers, including breast and colorectal cancer. ${ }^{12}$ ALK6 plays a role in chronic myeloid leukemia. ${ }^{9,15}$ ALK5 is reported to be a TGF $\beta$ receptor that is present in mesenchymal stem cells. ${ }^{16}$ The three type-II receptors are usually considered to have similar roles in the signaling pathway associated with BMPs (Ref. 3) but BMPR-II has likely been the most studied. Indeed, it was recently shown to play a protective role for endothelial cells from increased TGF $\beta$ responses and altered cell mechanics. ${ }^{17}$

BMP signaling is initiated by the binding of BMPs to type-I BMPRs with high affinity prompting the constitutively active type-II BMPRs to come in close proximity to the formed complex, and induce the transphosphorylation of the glycine/ serine-rich region (GS-box) preceding the kinase domain, thus leading to the formation of a ternary complex of BMP/type-I BMPR/type-II BMPR. ${ }^{1,18-20}$ In this signaling pathway, the high number of BMP ligands $(\simeq 20)$ compared to the low number of BMP receptors (four type-I and three type-II receptors) indicates the presence of a promiscuous mechanism in which a given
BMP can bind several receptors with distinct binding affinities. ${ }^{6,21}$ Furthermore, it has been reported that high affinity ligands can compete with low affinity ligands for the binding of BMPRs and, therefore, can antagonize their signaling. ${ }^{22}$ The previously described structures of several BMPs (BMP-2 pdb: 3BMP, BMP-7 pdb: 1BMP, BMP-9 pdb: 1ZKZ) lead us to gain insights into the structural differences between them. For example, it was described that most of the residues existing in BMP-2 wrist epitope are invariant or replaced by isofunctional side chains in BMP-7. Similarly, most binding residues in the knuckle region of BMP-2 are invariant in BMP-7 and BMP-4, suggesting that the specificity is only determined by a small subset of residues. ${ }^{23}$ However, comparative structural studies of the binding sites of BMP and BMPR are needed to better understand the cause of this promiscuous binding. A better knowledge of the detailed binding characteristics of the BMPs to the BMPRs will help us to identify the high affinity couples and to gain insight into the initiation of BMP signaling pathways.

The data available from the literature of BMP/BMPR interactions are assembled in Table I. To date, most of the characterizations of BMP/BMPR interactions have been determined using surface plasmon resonance (SPR), which can be considered as a gold standard in the field. However, the direct comparison of $\mathrm{K}_{\mathrm{D}}$ for the different BMPs and BMP receptors is difficult since data have been obtained using various experimental conditions (different protein constructs, different immobilization strategies, different buffers, different SPR instruments, etc.), which introduces a large variability in the experimental data. In addition, these data focused on particular BMP/BMPR couples and there is a lack of data for BMP-4 and 9 as well as for ALK1.

Among all the biophysical methods available today to characterize protein-protein interactions, reflectometric interference

TABLE I. Literature study of all the $\mathrm{K}_{\mathrm{D}}(\mathrm{nM})$ of the interactions between couples of BMP and their receptors (type-I and type-Il BMPRs). The experiments were usually performed in one of the two configurations: in red, when the BMPR is immobilized, and in blue, when the BMP is immobilized. BLI: biolayer interferometry, Confo: conformation, Tech. technique.

\begin{tabular}{|c|c|c|c|c|c|c|c|c|c|c|}
\hline $\begin{array}{l}\mathrm{K}_{\mathrm{D}} \\
(\mathrm{nM})\end{array}$ & Confo. & Tech. & ALK1 & ALK2 & ALK3 & ALK5 & ALK6 & BMPR-II & ACTR-IIA & ACTR-IIB \\
\hline \multirow[t]{3}{*}{ BMP-2 } & BMPR & SPR & & & $\begin{array}{c}0.004- \\
2.6^{23-28}\end{array}$ & & $11^{2.5-24,26-28}$ & $\begin{array}{c}45- \\
100^{23,24,27}\end{array}$ & $\frac{14-}{80^{23-25,27,30,31}}$ & \multirow[t]{3}{*}{$\begin{array}{c}6-36^{24,25,27} \\
8^{29}\end{array}$} \\
\hline & immobilized & BLI & & & $1.1^{29}$ & & $1.1^{29}$ & $26.7^{29}$ & $52.7^{29}$ & \\
\hline & $\begin{array}{c}\text { BMP } \\
\text { immobilized }\end{array}$ & SPR & N.D ${ }^{32}$ & $>400000^{33}$ & $10-330^{27,32,33}$ & & $95-350^{27,33}$ & & $3800-5400^{31,33}$ & \\
\hline \multirow[t]{2}{*}{ BMP-4 } & $\begin{array}{c}\text { BMPR } \\
\text { immobilized }\end{array}$ & SPR & & & $0.06^{28}$ & & $0.22^{28}$ & & & \\
\hline & $\begin{array}{c}\text { BMP } \\
\text { immobilized }\end{array}$ & SPR & & & $1.2-47^{34,35}$ & & & & & \\
\hline \multirow[t]{2}{*}{ BMP-7 } & $\begin{array}{c}\text { BMPR } \\
\text { immobilized }\end{array}$ & SPR & & $>500^{24,27}$ & $\frac{2-}{1680^{24,25,27,28}}$ & & $0.3-9^{24,27,28}$ & $25-100^{24,27}$ & $1-5 \cdot 1^{24,25,27,30,31}$ & \multirow[t]{2}{*}{$2-10^{24,25,27}$} \\
\hline & $\begin{array}{c}\text { BMP } \\
\text { immobilized }\end{array}$ & SPR & & $\begin{array}{c}55000- \\
143000^{31,33}\end{array}$ & $\begin{array}{c}1900- \\
10000^{27,33}\end{array}$ & & $750-1000^{27,33}$ & & $900-1700^{31,33}$ & \\
\hline \multirow[t]{2}{*}{ BMP-9 } & $\begin{array}{c}\text { BMPR } \\
\text { immobilized }\end{array}$ & SPR & $<0.008-0.045^{36-39}$ & & & & & $0.6-3.3^{36,37}$ & $6.4-42.7^{36,37}$ & \multirow[t]{2}{*}{$\begin{array}{c}0.02- \\
1.4^{36,37}\end{array}$} \\
\hline & $\begin{array}{c}\text { BMP } \\
\text { immobilized }\end{array}$ & SPR & $2-45^{32,39}$ & & N.D ${ }^{32}$ & & & & & \\
\hline
\end{tabular}


spectroscopy (RifS) $)^{40,41}$ is a label-free optical method based on white light interferences at layers of sensors. A commercially available setup, known as biolayer interferometry (BLI), enables us to perform parallel real-time binding measurements and characterization of biomolecule interactions. It is increasingly used to study kinetic constants and binding affinities of proteinprotein and protein-nucleic acid interactions, ${ }^{41-44}$ and it has only recently begun to be used to study BMP/activin A chimera interactions. $^{29}$

In the present study, our aim was to quantify in similar experimental conditions and a large set of BMP/BMPR interactions in a parallel manner, in order to directly compare their kinetic parameters and binding affinities. We decided to focus on four BMPs that are among the most widely studied: BMP-2, BMP-4, BMP-7, and BMP-9. ${ }^{45}$ For the type-I BMP receptors, we considered ALK1, ALK2, ALK3, ALK6, and added ALK5 known as an essential TGF $\beta$ receptor ${ }^{46}$ since it is involved in the signaling of BMP-responsive cells such as mesenchymal stem cells. ${ }^{16}$ We studied the three type-II BMP receptors (BMPR-II, ACTR-IIA, and ACTR-IIB).

\section{EXPERIMENT}

\section{A. Protein and reagents}

Apart from BMP-2 which was gifted by Bioventus (North Carolina, USA), BMPs and extracellular domains (ECDs) of the BMPR-FC chimeras were bought from Sigma Aldrich (Missouri, USA) and R\&D systems (Minnesota, USA), respectively. BMP-2 (Bioventus, North Carolina, USA) and BMP-7 (catalog number: 120-03P), as well as BMP-9 (catalog number: 120-07) (Peprotech, Rocky Hill, USA), are produced in Chinese hamster ovary (CHO) cells while BMP-4 (Catalog number 120-05ET) was produced in Escherichia coli (Peprotech, Rocky Hill, USA). The anti-hIgG Fc (AHC) capture biosensors were purchased from ForteBio (California, USA), and the SPR protein A-coated chips were purchased from GE Healthcare Life Sciences (Illinois, USA). The buffer was made of $20 \mathrm{mM}$ HEPES at $p \mathrm{H} 7.4$ with $150 \mathrm{mM} \mathrm{NaCl}$ (named hereafter HEPES-NaCl) and $0.02 \%$ Tween 20 while the regeneration buffer was made of $10 \mathrm{mM}$ glycine at $p \mathrm{H} 1.7$ (named hereafter regeneration buffer). They were all prepared in-house.

\section{B. BLI kinetics interaction experiments}

All the BLI experiments were performed using an OctetRED96e apparatus from Pall/FortéBio (California, USA) and data were recorded with the manufacturer software (Data Acquisition v11.11). All proteins were solubilized following the supplier instruction in the HEPES- $\mathrm{NaCl}$ buffer. The analysis protocol was adapted from previous studies. ${ }^{29,36}$ In detail, prior to any capture, the BMPR-Fc samples were first diluted in the HEPES-NaCl buffer. For the association phase, the BMPs were diluted in twofold serial dilutions in HEPES-NaCl buffer. $0.2 \mathrm{ml}$ of each sample and buffer were disposed in wells of black 96-well plates (Nunc F96 MicroWell, Thermo Fisher Scientific), maintained at $25^{\circ} \mathrm{C}$ and agitated at $1000 \mathrm{rpm}$ the whole time. Prior to each assay, all biosensors were prewetted in $0.2 \mathrm{ml}$ of HEPES-buffer for $10 \mathrm{~min}$, followed by monitored equilibration for 60 or $120 \mathrm{~s}$.
AHC capture biosensors (FortéBio) were loaded with each ligand for $200 \mathrm{~s}$ until reaching a spectrum shift between 0.8 and $1.1 \mathrm{~nm}$ depending on BMPR-Fc, followed by an additional equilibration step of 60 or $120 \mathrm{~s}$ in HEPES- $\mathrm{NaCl}$ buffer. Association phases were monitored during dipping the functionalized biosensors in analyte solutions of different concentrations between 2 and $80 \mathrm{nM}$ for $400 \mathrm{~s}$, and the dissociation phases in the buffer for $400 \mathrm{~s}$. To assess and monitor analyte unspecific binding, blank biosensors were treated with the same procedures but replacing the ligand solutions by analysis buffer. All sensors were fully regenerated between experiments with different BMPRs by dipping for $30 \mathrm{~s}$ in regeneration buffer. All measurements were performed three times in independent experiments.

Kinetics data were analyzed using the manufacturer software (Data analysis HT v11.1). The "blank" signal from the biosensor in the presence of the HEPES-NaCl buffer was subtracted from the signal obtained from each functionalized biosensor and each analyte concentration. The kinetic signals were then fitted using a global/local method and 1:1 Langmuir or 2:1 heterogeneous ligand model. Affinity constants were calculated from the ratio $\mathrm{k}_{\mathrm{d}} / \mathrm{k}_{\mathrm{a}}$ values. The reported values are given as mean \pm SD obtained from three independent experiments.

\section{Surface plasmon resonance experiments}

All surface plasmon resonance experiments were performed using a Biacore T200 apparatus (GE Healthcare Life Sciences/ Biacore, Illinois, USA) and data were recorded using the manufacturer software (Biacore control software v2.0). All protein samples were solubilized following the supplier instruction in the analysis buffer prior to any experiment. Prior to capture, the BMPR-Fc samples were first diluted in analysis buffer. For the association phase, BMP samples were diluted at concentrations between 0.2 and $6.4 \mathrm{nM}$ in twofold serial dilutions in the Hepes- $\mathrm{NaCl}$ buffer. Sensor chips and system were pre-equilibrated in the Hepes- $\mathrm{NaCl}$ buffer prior to any injection. The protein $\mathrm{A}$ sensor chips (GE Healthcare Lifesciences) were loaded by injecting each ligand for $100 \mathrm{~s}$ until they reach a signal level between 100 and 120 arbitrary response units depending of BMPR-Fc, followed by an additional equilibration step of several minutes in analysis buffer. Association phases were monitored during injections over the functionalized surfaces of analyte solutions of different concentrations for $300 \mathrm{~s}$, and the dissociation phases of analysis buffer for $300 \mathrm{~s}$. To assess and monitor analyte unspecific binding, blank surfaces were treated with the same procedures but replacing the ligand solutions by analysis buffer. All surfaces were fully regenerated between experiments with different BMPR-Fc by injecting for $30 \mathrm{~s}$ regeneration buffer. Two independent experiments were performed. Kinetic data were processed with the manufacturer software (Biacore Evaluation software v3.1). Signals from the reference surface were subtracted from the signals obtained from each functionalized ship. The resulting specific kinetic signals were then fitted using the 1:1 Langmuir model. Affinity constants were calculated from the ratio $\mathrm{k}_{\mathrm{d}} / \mathrm{k}_{\mathrm{a}}$ values. Reported values are obtained by averaging the values obtained from the replicates and reported errors as the standard deviation. 


\section{RESULTS}

We first performed a literature study to gain information on the state-of-the-art regarding BMP/BMPR interactions. Table I provides a view of the $K_{D}$ values, which are in the $n M$ range for the highest affinity interactions. Table S1 in the supplementary material $^{70}$ gives the detailed information obtained from each published study. We first note that all experiments, but one using the commercially available BLI setup, ${ }^{29}$ were conducted using SPR with two configurations to perform the experiments: the first configuration consists in immobilizing the BMPs on the sensor chip while the second consists in immobilizing the BMPRs, this second strategy being the most common. In terms of immobilization protocols, we noted that several strategies were proposed, which can be grouped into three major categories (Table S1 in the supplementary material): ${ }^{70}$ (i) using biotinylated BMPR coupled to streptavidin-coated surfaces; (ii) using BMPR-Fc captured on anti-Fc-coated sensors; and (iii) direct immobilization of BMPR using an amine coupling strategy.

Looking at the published studies (Table I and Table S1 in the supplementary material), ${ }^{70}$ it appears from a given BMP/BMPR couple that the range of measured $K_{D}$ can be very broad. These discrepancies likely arise from the differences in experimental details, including immobilization strategies, experimental working conditions, the usage of monomeric BMPR ectodomains, and the biochemistry of BMPs itself. Moreover, since BMP-2 and BMP-4 are usually considered to behave similarly, ${ }^{3}$ several studies were performed only on BMP-2 interaction with type-II BMPRs (BMPR-II, ACTR-IIA, and ACTR-IIB) and with type-I BMPR ALK2, but there is no such study for BMP-4. We also noted the unavailability of data for the interactions of BMP-2, 4, and 7 with ALK1 since it was reported to be the major BMP-9 receptor. ${ }^{11}$ Last, we noticed the absence of data on ALK5 (TGF $\beta$ R-I) with any of the chosen BMPs since it was traditionally considered solely as a TGF $\beta$ receptor $^{46}$ but was also shown to be a central point in BMP/TGF $\beta$ signaling. ${ }^{47}$

\section{A. Dimeric state of BMPs and BMPR}

The commercially available proteins that we used were produced in $\mathrm{CHO}$ for BMP-2, 7, and 9 or in E.coli for BMP-4. The BMPR coupled to $\mathrm{Fc}$ fragments (BMPR-Fc) were produced in mouse myeloma NS0 cells, except for ACTR-IIA that was produced in CHO cells. We verified the biochemical state (monomeric or dimeric) of all BMPs and BMPR-Fc by gel electrophoresis in both nonreducing and reducing conditions (Fig. S2 in the supplementary material). ${ }^{70}$ The BMPs were mostly dimeric, as expected ${ }^{6}$ and migrate at $\simeq 26 \mathrm{kDa}$ in nonreducing conditions, and at $\simeq 13 \mathrm{kDa}$ in reducing conditions. Since the Fc fragment form dimers, the BMPR chimeras are also present in the dimeric state and migrate at 90 and $110 \mathrm{kDa}$ in nonreducing condition and in a monomeric form with a band between 45 and $55 \mathrm{kDa}$ in reducing conditions (Fig. S2 in the supplementary material). ${ }^{70}$

\section{B. Immobilization of BMPR on the biosensor}

In vivo, the BMPs are soluble proteins that localize in the extracellular matrix or in blood for BMP-9. They can then be considered to diffuse freely in a 3D space. The BMPRs are transmembrane proteins that are localized at the cellular membrane and are thus diffusing in a $2 \mathrm{D}$ space. For this reason, it is likely that the order of magnitude of the diffusion of BMPR is similar to that of lipids in a membrane $\left(\simeq 1 \mu \mathrm{m}^{2} / \mathrm{s}\right)$ while that of BMPs is similar to a protein diffusing freely $\left(\simeq 100 \mu \mathrm{m}^{2} / \mathrm{s}\right){ }^{48}$ We thus choose to immobilize the BMPRs at the biosensor surface and to adsorb BMPs at their surface to better mimic the in vivo situation.

In order to find a protocol applicable to all BMP/BMPR couples, we considered several capture strategies for BMPR immobilization at the biosensor surface. The same previously published capture methods used for SPR, including biotinylated ligand/streptavidin surface, amine coupling absorption, or Fc chimera/antihuman IgG or protein A surfaces were considered (Table S1 in the supplementary material). ${ }^{70,23,26,30,31}$ Since all the BMPR-Fc chimeras were commercially available, and as anti-Fc fragment-coated biosensors are known to be more stable than protein $A,{ }^{29,36}$ we selected this strategy that consists in immobilizing the BMPR-Fc chimeras, formed by homodimers of BMPRs and an Fc fragment, to the anti-Fc-coated biosensor surfaces [Fig. 1(a) and material and methods]. This configuration presents the advantage of immobilizing all of the BMPR homogeneously in one orientation, with their binding site accessible to BMPs.

In order to determine a suitable adsorption density of the BMPRs on the biosensors, we performed preliminary assays with ALK3 receptor immobilized at increasing densities leading to a signal between 0.5 and $3 \mathrm{~nm}$ of spectral shift $(\mathrm{nm})$ after a fixed contact time of $150 \mathrm{~s}$. The functionalized surfaces were then set in contact with BMP-2 at a constant concentration of $5 \mathrm{nM}$ to proceed to BMP-2 adsorption [Fig. 1(b)]. From the response at equilibrium versus ALK3 concentration [Fig. 1(c)], we selected the concentration of ALK3 $\simeq 28 \mathrm{nM}$ as an optimal immobilization concentration, leading to an association signal of $\simeq 0.5 \mathrm{~nm}$ after $600 \mathrm{~s}$, since it is one of the lowest concentrations before saturation of the binding sites that yields an acceptable signal.

\section{Interaction of BMPs with type-I BMPR and type-II BMPR}

The kinetic interaction studies were then performed using the same protocol for the four BMPs with BMPRs. All BMPRs were adsorbed at densities corresponding to a spectral shift between 0.8 and $1.1 \mathrm{~nm}$. The BMP concentrations were varied over a large range ranging from 2 to $80 \mathrm{nM}$ (Fig. 2). Representative experimental curves for BMP-2/ALK3, BMP-9/ALK1, BMP-2/BMPR-II, and BMP-7/ACTR-IIA are shown in Fig. 2 (respectively, panels A-D).

To determine the kinetic parameters, the 1:1 Langmuir model binding model has been used. Indeed, it has been shown in structural studies ${ }^{23,30,49}$ that the BMP/BMP receptor interaction can be considered as bimolecular: It was reported that BMP dimers comprise two distinct pairs of binding sites: one for type-I BMPR, called "the wrist" and the other for type-II BMPR, called "the knuckle." While the type-I interface is a large continuous area formed by residues from both BMP monomers, the interface with type II is composed only of amino acids from one BMP monomer, ${ }^{5}$ as seen in the example of BMP-2/ALK3/ACTR-IIA (pdb: $2 \mathrm{H} 64)^{50}$ [Fig. 3(a)]. Thus, a one to one binding is expected. 

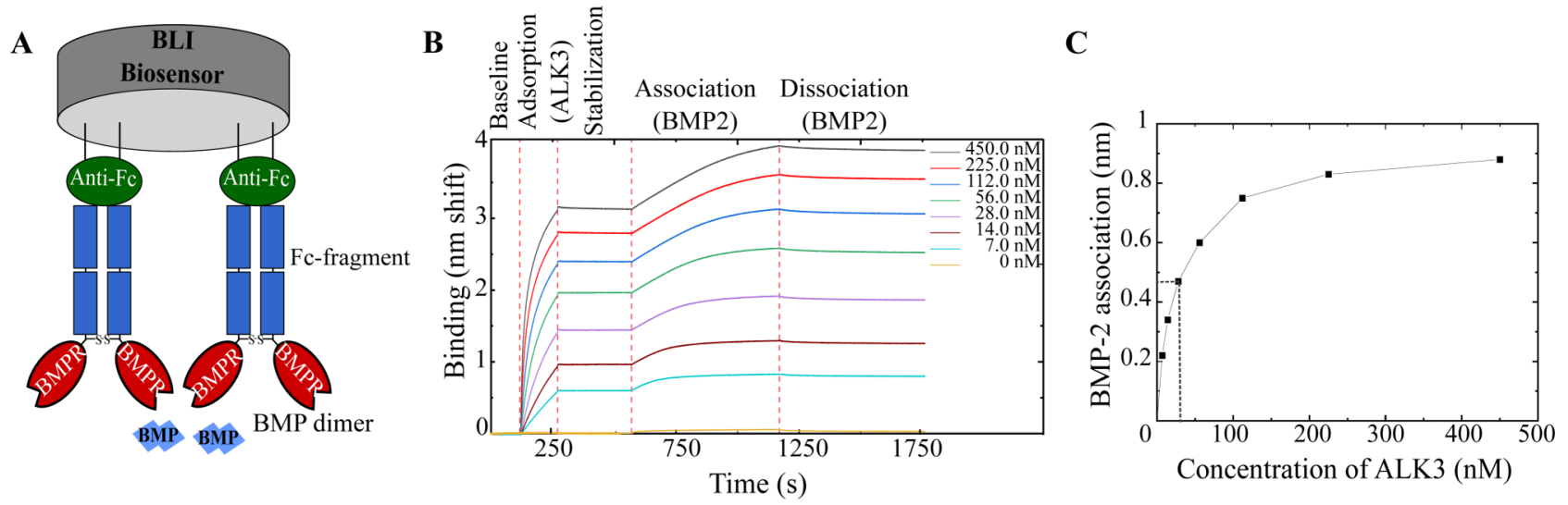

FIG. 1. Adsorption strategy of BMPR-Fc on the biosensors. (a) Schematic representation of the adsorption strategy where an anti-Fc-coated biosensor binds the Fc-receptor chimera. (b) Preliminary experiment where ALK3 receptor was adsorbed at increasing concentrations (from 7 to $450 \mathrm{nM}$ ) and set to interact with BMP-2 at a concentration of $5 \mathrm{nM}$. (c) The interaction signal of BMP-2 to ALK3 given in nm shift, plotted as a function of ALK3 initial concentration in solution. Data were obtained using OctetRED96e.

In the present case, since the Fc chimera induces dimerization of the BMPR, two possible binding modes are possible [Figs. 3(b)-3(e)]: one BMP molecule binding to two proximate BMPR binding domains (model $\mathrm{B}$ or D) or one BMP molecule binding to one BMPR binding domain (model $\mathrm{C}$ or $\mathrm{E}$ ). Nonetheless, since BMP
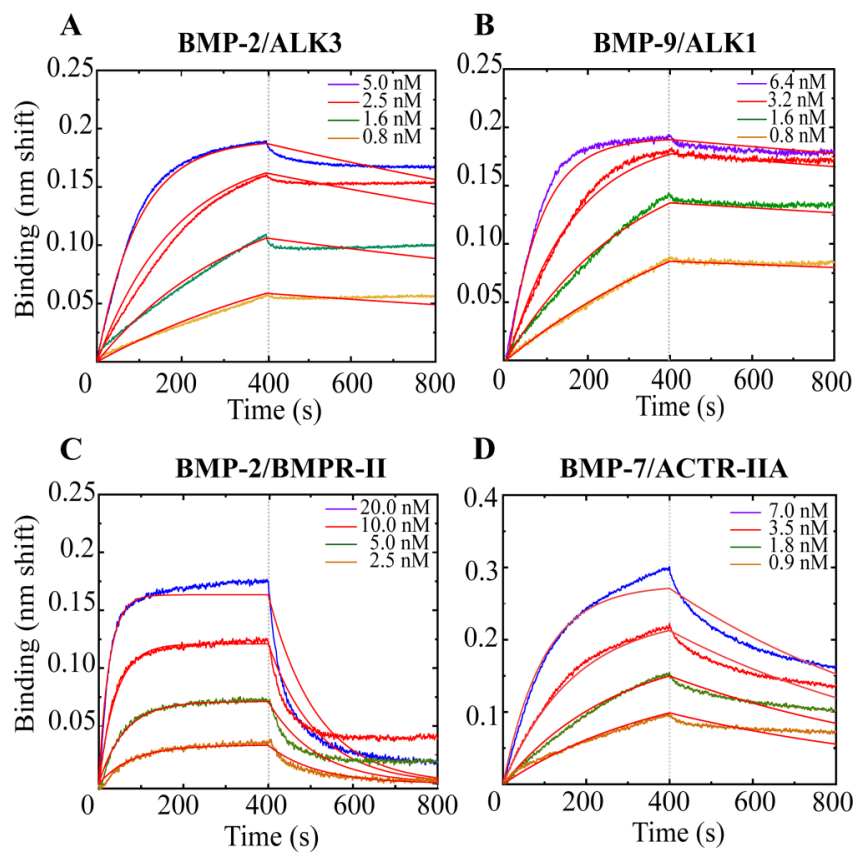

FIG. 2. Examples of binding kinetics between type-I BMPRs and BMPs. (a) BMP-2/ALK3, (b) BMP-9/ALK1 and between type-II BMP and BMPs, with (c) BMP-2/BMPR-II and (d) BMP-7/ACTR-IIA. Data were obtained using OctetRED96e. The 1:1 Langmuir fit was used to fit the experimental data. dimers are fully symmetrical, all binding models may lead to $1: 1$ binding kinetic. It could be argued that a phenomenon of avidity could be occurring in the Figs. 3(b)-3(d), and a more complicated model should be applied. Nevertheless, to be consistent with the literature, we applied the commonly used 1:1 Langmuir model to fit the experimental data as it has been regularly employed in previous studies, notably in the ones with an Fc adsorption strategy, and in the one using BLI technique to determine kinetics parameters. ${ }^{25,29,31,36}$ Furthermore, the $\mathrm{R}^{2}$ values of the fits, presented in Tables S3 and S4 in the supplementary material, ${ }^{70}$ are in majority around 0.95 and higher, which indicates an acceptable fit.

A fast association was generally observed for all the BMPs interacting with the type-I BMPR, but differences in the dissociation rate are seen. The association constant $\left(\mathrm{k}_{\mathrm{a}}\right)$ and the dissociation constant $\left(\mathrm{k}_{\mathrm{d}}\right)$ that were extracted from the fit of each interaction curve are presented in Fig. 4 as well as in Tables S3 and $\mathrm{S} 4$ in the supplementary material. ${ }^{70}$ BMP-2 and BMP-4 exhibit a high $\mathrm{k}_{\mathrm{a}}\left(\simeq 15 \times 10^{5} \mathrm{M}^{-1} \mathrm{~s}^{-1}\right.$ for BMP-2 and $\simeq 5 \times 10^{5} \mathrm{M}^{-1} \mathrm{~s}^{-1}$ for BMP-4), and low $\mathrm{k}_{\mathrm{d}}$ with both ALK3 and ALK6 $\left(\simeq 0.5 \times 10^{-3} \mathrm{~s}^{-1}\right.$ for BMP-2 and $\simeq 1.5 \times 10^{-3} \mathrm{~s}^{-1}$ for BMP-4), indicating a fast association and slow dissociation to these receptors. Furthermore, BMP-2 associates and dissociates in a similar manner to ALK1, ALK2, ALK5 $\left(\mathrm{k}_{\mathrm{a}} \simeq 4 \times 10^{5} \mathrm{M}^{-1} \mathrm{~s}^{-1}\right.$ and $\left.\mathrm{k}_{\mathrm{d}} \simeq 3 \times 10^{-3} \mathrm{~s}^{-1}\right)$ and to the three type-II BMPRs $\left(\mathrm{k}_{\mathrm{a}} \simeq 11 \times 10^{5} \mathrm{M}^{-1} \mathrm{~s}^{-1}\right.$ and $\left.\mathrm{k}_{\mathrm{d}} \simeq 6 \times 10^{-3} \mathrm{~s}^{-1}\right)$. In comparison to BMP-2, BMP-4 associates more slowly to these receptors.

BMP-7 demonstrates a slow association to all the type-I BMPRs $\left(\simeq 2 \times 10^{5} \mathrm{M}^{-1} \mathrm{~s}^{-1}\right)$, in addition to a slow association $\left(\simeq 6 \times 10^{5} \mathrm{M}^{-1} \mathrm{~s}^{-1}\right)$ and dissociation $\left(\simeq 2 \times 10^{-3} \mathrm{~s}^{-1}\right)$ to type-II BMPRs. Regarding BMP-9, it exhibits a fast association $\left(15.0 \pm 3.5 \times 10^{5} \mathrm{M}^{-1} \mathrm{~s}^{-1}\right)$ and a very slow dissociation $\left(0.2 \pm 0.1 \times 10^{-3} \mathrm{~s}^{-1}\right)$ to ALK1 and type-II BMPR $\left(\mathrm{k}_{\mathrm{a}} \simeq 20 \times 10^{5} \mathrm{M}^{-1} \mathrm{~s}^{-1}\right.$ and $\left.\mathrm{k}_{\mathrm{d}} \simeq 3.3 \pm \times 10^{-3} \mathrm{~s}^{-1}\right)$. BMP-9 also presents a slow association and fast dissociation from ALK2 and ALK5 $\left(\mathrm{k}_{\mathrm{a}} \simeq 2 \times 10^{5} \mathrm{M}^{-1} \mathrm{~s}^{-1}\right.$ and $\left.\mathrm{k}_{\mathrm{d}} \simeq 3 \times 10^{-3} \mathrm{~s}^{-1}\right)$, but it does not interact with ALK3 and ALK6. 
A

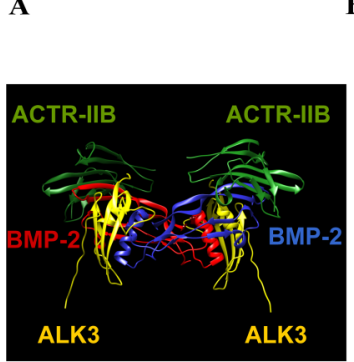

B

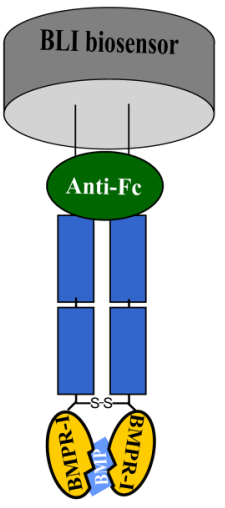

C

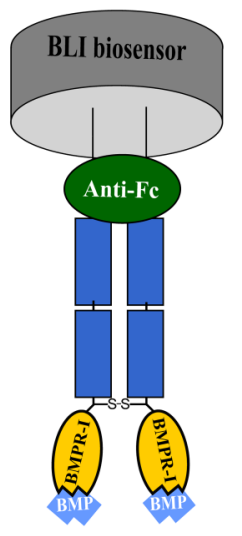

D

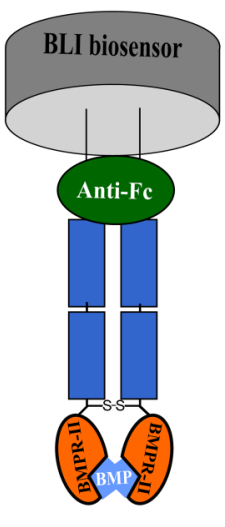

E

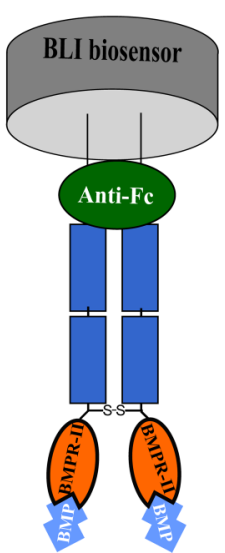

FIG. 3. Schematic representation of the different binding models in the BLI BMP/BMPR interaction. (a) Picture of BMP-2/ALK3/ACTR-IIB ternary complex (pdb:2H64) adapted from Weber et al., BMC Struct. Biol. 7, $1(2007){ }^{50}$ (b) Association of the two binding sites of BMP dimer to two type-I BMPR. (c) Association of one binding site of BMP dimer with one type-I BMPR. (d) Association of the two binding sites of BMP with two type-II BMPR. (e) Association of one binding site of BMP dimer with type-II BMPR.

Next, we calculated the equilibrium affinity constant $K_{D}$ (equal to the ratio of $k_{d}$ over $k_{a}$ ). BMPs present a generally high affinity to all BMPRs ranging from 133 to $0.2 \mathrm{nM}$ for high affinity interactions. The lowest $\mathrm{K}_{\mathrm{D}}$ values are highlighted in dark blue color (Table II).

BMP-2 and BMP-4 have a good binding affinity to both ALK3 and ALK6 since their $\mathrm{K}_{\mathrm{D}}$ was $<3 \mathrm{nM}$ [Table II(a)]. They bind to ALK2 similarly with an affinity of $7.0 \pm 2.3 \mathrm{nM}$ for BMP-2 and $10.5 \pm 3.8 \mathrm{nM}$ for BMP-4. They also bind to ALK1 and ALK5 but BMP-2 has an approximately fourfold higher affinity to these receptors than BMP-4. Regarding type-II BMPRs, BMP-2 had a similar affinity for both ACTR-IIA and ACTR-IIB $(\simeq 6 \mathrm{nM})$ while BMP-4 also interacted with both receptors although with an approximately fourfold lower affinity $(\simeq 23 \mathrm{nM})$. In addition, BMP-2 has also a tenfold higher affinity for BMPR-II than BMP-4. We then investigated whether the differences between BMP-2 and BMP-4 may arise from their glycosylation state since BMP-2 is produced in $\mathrm{CHO}$ while BMP-4, being produced in E-coli, is nonglycosylated. We thus compared the interactions of ALK3 with both the glycosylated and nonglycosylated forms of BMP-4 (Fig. S5 in the supplementary material). ${ }^{70}$ For the glycosylated form of BMP-4, the increase in the nonspecific signal was negligible $(\simeq 0.02 \mathrm{~nm})$. However, the interactions differed slightly since $K_{D}$ was $1.32 \pm 0.48 \mathrm{nM}$ for the nonglycosylated BMP-4, versus $0.3 \pm 0.06 \mathrm{nM}$ for the glycosylated form.

BMP-7 interacts with all type-I BMPRs with similar affinities $(\simeq 20 \mathrm{nM})$. In contrast, it has a greater affinity for the three type-II BMPRs as it binds to BMPR-II and ACTR-IIB similarly $(\simeq 6 \mathrm{nM})$ and to ACTR-IIA with a fivefold to sevenfold higher affinity $(1.3 \pm 0.3 \mathrm{nM})$.

Regarding BMP-9, it binds ALK1 with high affinity $(0.2 \pm 0.1 \mathrm{nM})$ and ALK5 and ALK2 with a much lower affinity $(51.0 \pm 18.3 \mathrm{nM}$ and $133.1 \pm 35.1 \mathrm{nM}$, respectively). The affinity of BMP-9 for all the three
type-II BMPRs is high: $0.8 \pm 0.2 \mathrm{nM}$ for BMPR-II, $1.7 \pm 0.1 \mathrm{nM}$ for ACTR-IIA, and $1.4 \pm 0.4 \mathrm{nM}$ for ACTR-IIB. Notably, BMP-9 affinity for BMPR-II is about twofold higher in comparison to ACTR-IIA and ACTR-IIB.

Thus, the $K_{D}$ values indicated that there are notable differences between BMP-2 and BMP-4, a higher affinity of BMP-7 to type-II BMPRs in comparison to type-I BMPR, and a highly selective affinity of BMP-9 for ALK1 as well as to all type-II BMPRs.

In order to compare the BLI technique to SPR (Table I), we performed SPR kinetic experiments for selected high affinity couples, namely, BMP-9/ALK1 and BMP-2 or BMP-4/ALK3 or ALK2. For this purpose, we used commercially available protein A-coated chips and BMPR-Fc chimera as an adsorption strategy [Fig. 5(a)]. Unfortunately, the BMP-2/ALK3 (Fig. S6 in the supplementary material), ${ }^{70}$ BMP-2/ALK2, BMP-4/ALK3 (data not shown) kinetic interaction using this adsorption strategy could not be measured since nonspecific binding to the sensor ship was too high and specific binding signal could not be resolved (Fig. S6 in the supplementary material). ${ }^{70}$ In contrast, the BMP-9/ALK1 interaction was notable and a $\mathrm{K}_{\mathrm{D}}$ of $13.4 \mathrm{pM}$ was obtained. This value is 15 -fold lower than obtained by BLI $[\simeq 200$ pM-Fig. 5(b)].

\section{Interaction of BMPs with type-I BMPR/type-II BMPR ternary complex}

Next, we decided to investigate the interactions of BMP to type-I/type-II BMPR complexes. In vivo, it is reported that BMPs first bind to the inactive type-I BMPRs, thus triggering type-II BMPRs to activate (by phosphorylation) the type-I BMPRs by forming a ternary complex. ${ }^{31,51}$ We studied ALK2 as a type-I BMPR and all three type-II BMPRs with BMP-2, BMP-4, and BMP-7. We chose ALK2 since it is a well-studied receptor involved in several diseases and has a middle range affinity for the BMPs. 
A

$\mathbf{k}_{\mathrm{a}}$ BMP/BMPR-I

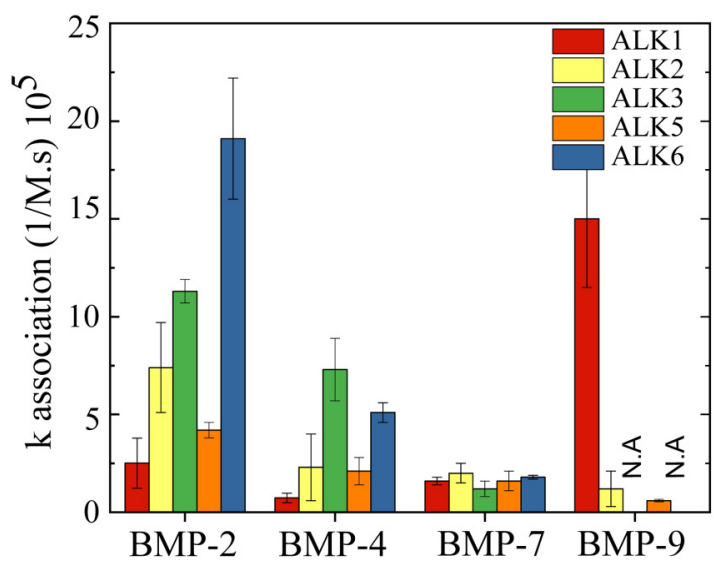

C

$\mathbf{k}_{\mathbf{a}}$ BMP/BMPR-II

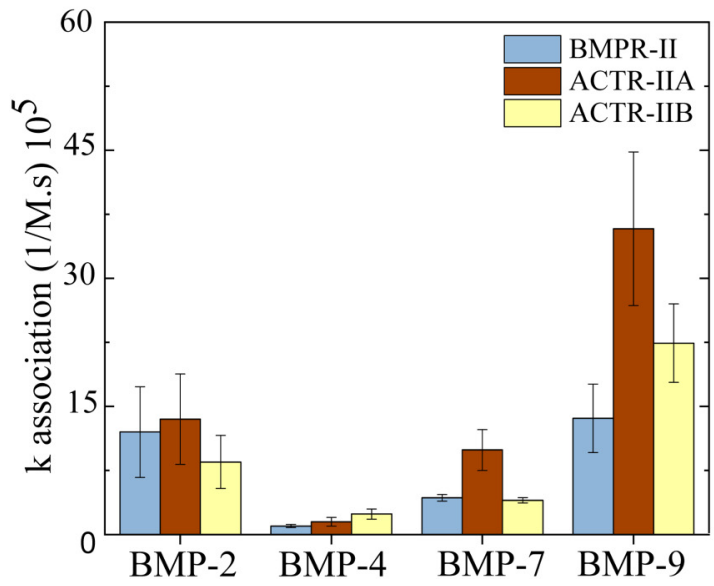

B

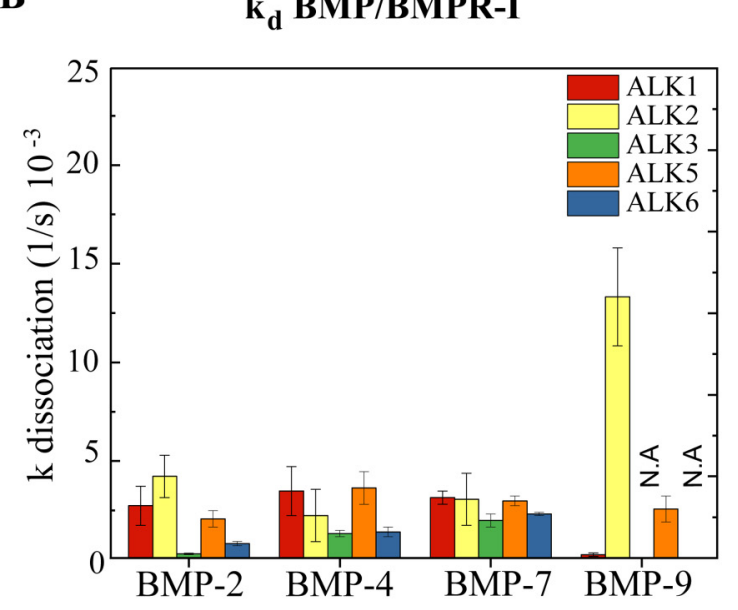

D

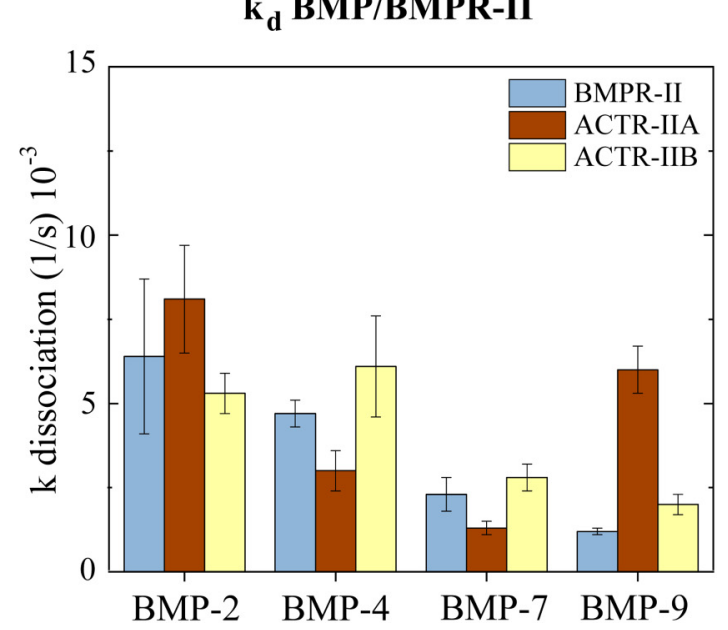

FIG. 4. Histograms presenting the association constants $\left(k_{a}\right)$ and the dissociation constants $\left(k_{d}\right)$. $k_{a}$ of $(a)$ BMP/type-I BMPR and (b) BMP/type-II BMPR interactions and $k_{d}$ of (c) BMP/type-I BMPR and (d) BMP/type-II BMPR interactions. For BMP-9/ALK3 and BMP-9/ALK6, the signal was very low (NA). The error bars represent the SD $(n=3)$.

Our experimental approach consisted in loading sequentially both types of BMP receptors on the biosensor [Figs. 6(a) and 6(b)]. We performed experiments using two capture strategies. First, ALK2 was loaded, followed by a type-II BMPR and then BMP-2 was set into contact with the functionalized surfaces [Fig. 6(a)]. Second, a reverse sequence was used in which ACTR-IIB was captured first, followed by ALK2 and then BMP-2 [Fig. 6(b)]. The adsorption times were chosen such as to have an equivalent level of adsorption for each receptor, with a total shift being similar to the case of single BMP/BMPR interactions.

To process and fit the kinetic data, we initially applied a 1:1 Langmuir model but the fit was of poor quality (Fig. S7 in the supplementary material). ${ }^{70}$ These interactions consist of two different receptors and, therefore, possess two pairs of two distinct binding sites for type-I and type-II BMPRs. We thus presumed that both types of type-I and type-II receptors bind BMPs separately with different affinities and, therefore, applied a 2:1 heterogeneous binding model.

The $K_{D}$ value in the configuration where ALK2 was immobilized first was $46.1 \pm 11.5 \mathrm{nM}$ for the first binding site and $14.4 \pm 2.3$ for the second. Conversely, when BMPR-II was adsorbed first, the $\mathrm{K}_{\mathrm{D} 1}$ value was $22.9 \pm 1.9 \mathrm{nM}$ and $\mathrm{K}_{\mathrm{D} 2} 4.6 \pm 0.2 \mathrm{nM}$ [Fig. 6(c)]. The same experiment was also performed for ALK2/BMPR-II/BMP-7 resulting in a $K_{D}$ of $4.6 \pm 0.7 \mathrm{nM}$ and $19.1 \pm 6.4 \mathrm{nM}$ for the experiment where ALK2 was adsorbed first, compared to $5.4 \pm 0.2$ and $23.2 \pm 0.1 \mathrm{nM}$ for the reverse order. In the case of BMP-7, binding is similar whatever the order of receptor presentation. 
TABLE II. Binding affinities ( $K_{D}$ in $\left.n M\right)$ of BMP/BMPR interactions. Tables summarizing the $K_{D}(n M)$ of the BMP/BMPR interactions for (a) type-I and (b) type-II receptors, obtained from the kinetic experiments in a conformation where the BMPR is immobilized. The interactions between BMP-9/ALK3 and BMP-9/ALK6 yielded a very low signal (NA). The high affinity couples are colored in dark blue. The error values represent the SD $(n=3)$.

\begin{tabular}{|c|c|c|c|c|c|}
\hline \multirow[b]{2}{*}{ BMP } & \multicolumn{5}{|c|}{ BMPR } \\
\hline & ALK1 & ALK2 (ACTR-I) & ALK3 (BMPR-IA) & ALK5 (TGFßR-I) & ALK6 (BMPR-IB) \\
\hline \multicolumn{6}{|l|}{ (a) } \\
\hline BMP-2 & $13.0 \pm 1.6$ & $7.0 \pm 2.3$ & $0.21 \pm 0.03$ & $5.8 \pm 1.1$ & $0.5 \pm 0.1$ \\
\hline BMP-4 & $55.4 \pm 4.0$ & $10.5 \pm 3.8$ & $1.7 \pm 0.5$ & $21.9 \pm 6.6$ & $3.1 \pm 0.3$ \\
\hline BMP-7 & $23.1 \pm 2.1$ & $18.4 \pm 3.8$ & $19.0 \pm 2.1$ & $22.6 \pm 1.1$ & $15.0 \pm 1.2$ \\
\hline BMP-9 & $0.2 \pm 0.1$ & $133.1 \pm 35.1$ & NA & $51.0 \pm 18.3$ & NA \\
\hline \multirow[t]{2}{*}{ BMP } & \multicolumn{3}{|c|}{ BMPR } & & \\
\hline & BMPR-II & ACTR-IIA & ACTR-IIB & & \\
\hline \multicolumn{6}{|l|}{ (b) } \\
\hline BMP-2 & $5.4 \pm 0.8$ & $6.1 \pm 1.2$ & $6.3 \pm 3.4$ & & \\
\hline BMP-4 & $56.0 \pm 6.0$ & $21.4 \pm 3.7$ & $26.0 \pm 0.5$ & & \\
\hline BMP-7 & $5.5 \pm 1.2$ & $1.3 \pm 0.3$ & $7.1 \pm 0.7$ & & \\
\hline BMP-9 & $0.8 \pm 0.2$ & $1.7 \pm 0.1$ & $1.4 \pm 0.4$ & & \\
\hline
\end{tabular}

The binding affinities for all the experiments where ALK2 is loaded first are summarized in Table III. Surprisingly, we did not find any improvements in the $\mathrm{K}_{\mathrm{D}}$ values when two receptors are captured on the biosensor surfaces compared to the situation when only one is present. The $\mathrm{K}_{\mathrm{D}}$ values for all of the experiments appear to be higher than the $\mathrm{K}_{\mathrm{D}}$ values of the simple BMP/BMPR interactions, indicating a lower affinity. In more detail, the values of the two $K_{\mathrm{D}}$ 's may be attributed to the values of two different types of binary interaction (BMP/ALK2 or BMP/type-II BMPR), such as the interaction BMP-7/ALK2/BMPR-II, where $\mathrm{K}_{\mathrm{D}} 1=4.6 \pm 0.7 \mathrm{nM}$ and $\mathrm{K}_{\mathrm{D}} 2=19.1 \pm 6.4 \mathrm{nM}$ (Table III), compared to $18.4 \pm 3.8 \mathrm{nM}$ for
A

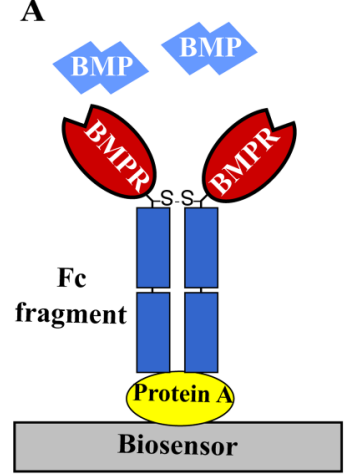

B

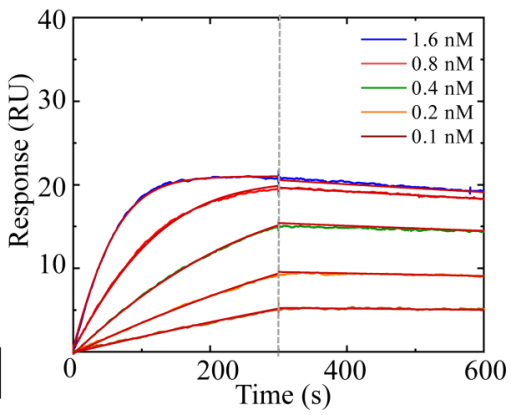

FIG. 5. SPR study of BMPR/BMP interactions. (a) A schematic representation of an SPR biosensor surface where the interaction was studied. Protein $A$ was used to immobilize the BMPR-Fc fragment. (b) Example of the kinetic experiment for the ALK1/BMP-9 couple showing the association phase (up to $300 \mathrm{~s}$ followed by the dissociation phase). The 1:1 Langmuir fit was used to fit the experimental data.
ALK2 and $5.5 \pm 1.2 \mathrm{nM}$ for BMPR-II in the binary experiments (Table II). Nevertheless, this observation was not observed for other interactions. These results suggest the complexity of the interactions occurring on the surface.

\section{DISCUSSION}

In this study, we performed experiments using the dimeric form of BMPs and BMPRs as confirmed by gel electrophoresis migration analysis (Fig. SI.1 in the supplementary material). ${ }^{70}$ Indeed, some coimmunoprecipitation studies in vitro showed that apart from being homodimers, receptors can be heterodimers (i.e., ALK2/ALK3 heterodimers), in the presence of BMP. ${ }^{52}$ However, the presence of homodimer receptors is regularly described. ${ }^{1,53}$ Thus, our aim in using dimers of BMPs and BMPRs was to mimic utmost the in vivo interactions at the cell surface. In that context, we used a simple adsorption strategy involving BMPR-Fc chimera that induces the dimerization of the receptors and presents them, contrary to other adsorption strategies, in a homogeneous manner on the surface with their binding site accessible.

Using BLI, we quantified the binding affinities of the four BMPs with the eight different BMPRs in similar experimental conditions. As we showed with our SPR data, several BMPR/BMP couples (ALK3/BMP-2, ALK3/BMP-4, and ALK2/BMP-2) could not be analyzed by SPR using the same strategy as BLI with protein A-coated sensors (Fig. S6 in the supplementary material), ${ }^{70}$ while BMP-9/ALK1 was detected (Fig. 5). There may be nonspecific adsorption of BMP-2 and 4 to protein A. The direct comparison of BLI versus SPR for the high affinity couple ALK1/BMP-9 showed that $K_{D}$ measured by BLI was 15 -fold lower than that measured by SPR (13.4 vs 200 pM) (Fig. 5). These differences between both techniques may be explained by the physical and chemical differences of the techniques since the thickness and composition of the sensor layers as well as the adsorption strategies are different. 

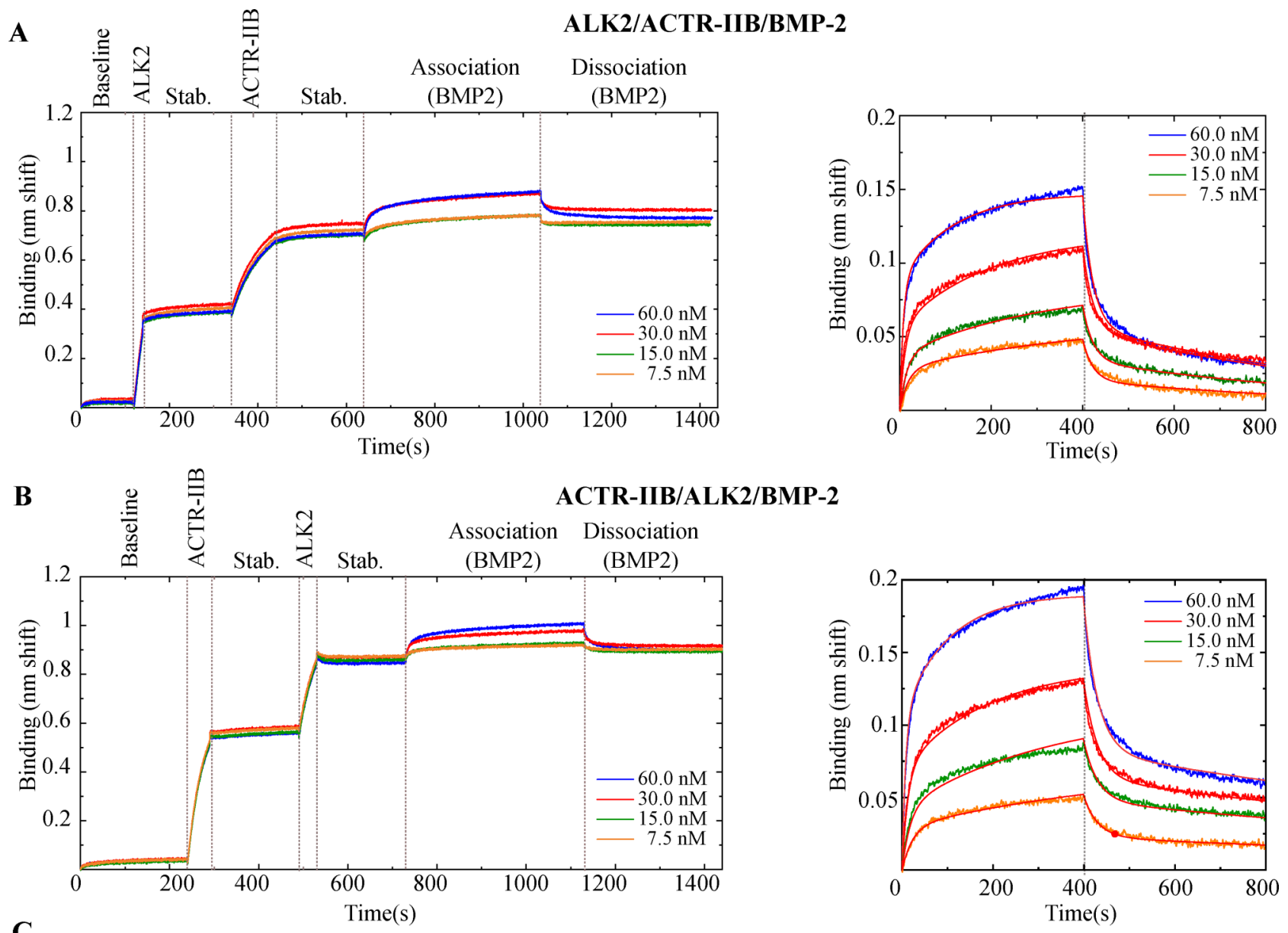

C

\begin{tabular}{|l|c|c|c|c|c|c|c|c|}
\hline & $\begin{array}{c}\text { Loading } \\
\text { ALK2 } \\
(\mathrm{s})\end{array}$ & $\begin{array}{c}\text { Loading } \\
\text { ACTR-IIB } \\
(\mathrm{s})\end{array}$ & $\begin{array}{c}\mathrm{K}_{\mathrm{D} 1} \\
(\mathrm{nM})\end{array}$ & $\begin{array}{c}\mathrm{k}_{\mathrm{a} 1} \\
\left(\mathrm{M}^{-1} \cdot \mathrm{s}^{-1}\right) \\
10^{5}\end{array}$ & $\begin{array}{c}\mathrm{k}_{\mathrm{d} 1} \\
\left(\mathrm{~s}^{-1}\right) \\
10^{-3}\end{array}$ & $\begin{array}{c}\mathrm{K}_{\mathrm{D} 2} \\
(\mathrm{nM})\end{array}$ & $\begin{array}{c}\mathrm{k}_{\mathrm{a} 2} \\
\left(\mathrm{M}^{-1} \cdot \mathrm{s}^{-1}\right) \\
10^{5}\end{array}$ & $\begin{array}{c}\mathrm{k}_{\mathrm{d} 1} \\
\left(\mathrm{~s}^{-1}\right) \\
10^{-3}\end{array}$ \\
\hline Loading order & First & Second & \multicolumn{7}{|c|}{} \\
\hline ALK2/ACTR-IIB & 20 & 100 & $46.1 \pm 11.5$ & $12.2 \pm 3.1$ & $56.2 \pm 20.3$ & $14.4 \pm 2.3$ & $1.09 \pm 0.01$ & $1.6 \pm 0.1$ \\
\hline Loading order & Second & First & \multicolumn{10}{|c|}{} \\
\hline ACTR-IIB/ALK2 & 50 & 40 & $22.9 \pm 1.9$ & $22.2 \pm 9.9$ & $50.9 \pm 0.3$ & $4.6 \pm 0.2$ & $2.3 \pm 1.1$ & $1.1 \pm 0.5$ \\
\hline
\end{tabular}

FIG. 6. Interaction between the ALK2/ACTR-IIB heterocomplex and BMP-2. Binding was done sequentially: ALK2 or ACTR-IIB first followed by the second receptor and then BMP-2. (a) First ALK2 or (b) first ACTR-IIB. The plots on the right panel represent a zoomed view of the association and dissociation steps of the corresponding full sensograms on the left. (c) Table summarizing the kinetic parameters deduced from the experimental fit to the data. The stab. step refers to stabilization. Data were obtained using OctetRED96e. The 2:1 heterogeneous ligand model was used to fit the experimental data.

Another aspect to mention is the sensitivity of the method and the stability of the baseline signal since the dissociation rate measured is sometimes at the limits of the instrument stability. Altogether, our experimental results show that the BLI technique is well adapted in our study to gain quantitative information on a large range of BMP/BMPR couples.

To date, BMP-4 has barely been studied since it was often considered to exhibit a very close behavior to BMP- $2 .{ }^{5}$ Our study first confirmed that both BMP-2 and BMP-4 bind to ALK3 and ALK6 with high affinity (Table I), as already mentioned in the literature. ${ }^{6,29}$ Additionally, our data reveal notable differences in the binding behaviors of BMP-2 and BMP-4. Indeed, BMP-2 binds to type-I BMPRs with a threefold higher affinity than BMP-4 (Table II). Interestingly, the difference arises mainly from a difference in association rates to the receptors, which was faster for BMP-2 than BMP-4, while the dissociation rates were similar 
TABLE III. Binding affinities $\left(K_{D}\right)(n M)$ of BMP/BMPR-I/BMPR-II interactions. Table summarizing the $K_{D} 1$ and $K_{D} 2$ values (nM) of the BMP/BMPR-//BMPR-II interactions obtained from the kinetic experiments in a conformation where ALK2 and type-II BMPR are loaded sequentially. The error values represent the SD $(n=3)$.

\begin{tabular}{|c|c|c|c|c|c|c|}
\hline \multirow[b]{3}{*}{$\mathrm{K}_{\mathrm{D}}(\mathrm{nM})$} & \multicolumn{6}{|c|}{ ALK2 (ACTR-I) } \\
\hline & \multicolumn{2}{|c|}{ BMPR-II } & \multicolumn{2}{|c|}{ ACTR-IIA } & \multicolumn{2}{|c|}{ ACTR-IIB } \\
\hline & $\mathrm{K}_{\mathrm{D} 1}$ & $\mathrm{~K}_{\mathrm{D} 2}$ & $\mathrm{~K}_{\mathrm{D} 1}$ & $\mathrm{~K}_{\mathrm{D} 2}$ & $\mathrm{~K}_{\mathrm{D} 1}$ & $\mathrm{~K}_{\mathrm{D} 2}$ \\
\hline BMP-2 & $17.8 \pm 7.2$ & $33.0 \pm 10.2$ & $31.7 \pm 6.5$ & $47.8 \pm 4.5$ & $14.4 \pm 2.3$ & $46.1 \pm 11.4$ \\
\hline BMP-4 & $55.8 \pm 17.2$ & $90.7 \pm 33.3$ & $14.1 \pm 2.5$ & $125.0 \pm 20.4$ & $88.7 \pm 22.6$ & $103.2 \pm 39.0$ \\
\hline BMP-7 & $4.6 \pm 0.7$ & $19.1 \pm 6.4$ & $7.1 \pm 1.8$ & $350.6 \pm 12.3$ & $19.1 \pm 5.5$ & $60.7 \pm 22.9$ \\
\hline
\end{tabular}

(Fig. 3). Particularly, the strongest differences were observed for the type-II BMPR, with faster association rates for BMP-2 for all the three receptors and faster dissociation rates for BMP-2 solely for BMPR-II and ACTR-IIA.

Our results are in agreement with previously published cellular data highlighting the distinct role of BMP-4 and BMP-2. One study examined their role in chondrocyte proliferation and found that the deletion of BMP-2 gene alone resulted in severe chondrodysplasia while the deletion of BMP-4 led to a minor cartilage phenotype. ${ }^{54}$ Likewise, in acute myeloid leukemia, a distinct role of BMP-4 versus BMP-2 has been evidenced: ${ }^{55,56}$ BMP-4 solely is involved as it activates a specific signaling pathway promoting immature resistant leukemic cells, which eventually leads to a relapse after treatment. ${ }^{55,56}$ In view of our findings regarding the specific differences between BMP-2 and BMP-4, it will be interesting to further evaluate their specific functions in different cell signaling contexts.

It is also noteworthy that the average binding of BMPs $(-2,4,7)$ to ALK2 is in the same range $\simeq 7-20 \mathrm{nM}$, and with a lower affinity to BMP-9 $(133 \mathrm{nM})$. In addition to the lower affinity of BMP-2 for type-II BMPRs compared to type-I BMPRs, we observed faster kinetic constants $\left(k_{a}, k_{d}\right)$ for type-II BMPRs (Fig. 3). This observation was previously reported and assumed to be the reason why BMP-2 and BMP-4 are recruited in a sequential order, with an initial binding to the higher affinity type-I BMPRs. ${ }^{21}$ It may be interesting to further study BMP/ALK2 interactions in the context of the R206H mutation, which is associated to FOP: this mutation leads to the activation of BMP signaling in the absence of BMP and to an enhanced biochemical signal in the presence of BMP. ${ }^{57}$

Our results showed that BMP-7 binds similarly to all ALKs with an affinity of $\simeq 20 \mathrm{nM}$, in agreement with the literature review (Table I), although the range of previously reported $\mathrm{K}_{\mathrm{D}}$ was large. With respect to type-II BMPRs, we found that BMP-7 binds with high affinities to the three type-II BMPRs, with a fivefold higher affinity for ACTR-IIA [Table II(b)]. A previous study reported that BMP-7 signals through ACTR-IIA. ${ }^{58}$ Notably, BMP-7 was also reported to induce chemotaxis in monocytic cells through BMPR-II and ACTR-IIA receptors but not through ACTR-IIB. ${ }^{5}$

Previous studies on BMP-9 have shown that it binds to ALK1 and ALK5 in endothelial cells ${ }^{59-61}$ and to ALK1 and ALK2 in mesenchymal cells used for osteogenic differentiation. ${ }^{62}$ Our data showing that BMP-9 binds ALK1 with a high affinity $(0.2 \pm 0.1 \mathrm{nM})$ and ALK2/ALK5 with a lower affinity $(133.1 \pm 35.1$ and $51.0 \pm 18.3 \mathrm{nM}$, respectively) $[$ Table $\mathrm{II}(\mathrm{a})]$ indicated that all these three ALK receptors are important in the signaling of BMP-9. The comparison of the structural data between both complexes BMP-2/ALK3-ECD/ ACTR-2B-ECD and BMP-9/ALK1-ECD/ACTR-2B-ECD shows that ALK1 has a distinct interface with BMP-9 and presents several structural differences compared to other type-I BMPRs. These structural disparities may well explain the low affinity of ALK1 for all the other BMPs, ${ }^{36}$ as seen in our data. Regarding the type-II BMPRs, former studies have shown that BMP-9 can bind to all of them. ${ }^{59,63}$ Our results indicated that BMP-9 bound all type-II BMPR with a very high affinity $(\sim 0.8-1.7 \mathrm{nM})$ and with a slightly higher affinity for BMPR-II $(0.8 \pm 0.2 \mathrm{nM})$ (Table II), in concert with the literature ${ }^{36,37}$ (Table SI.1 in the supplementary material). ${ }^{70}$

Interestingly, our results showed that there is a binding of several BMPs to ALK5 [Fig. 4 and Table II(a)]. We observed average affinities of BMP-2 $(5.8 \pm 1.1 \mathrm{nM}), \mathrm{BMP}-4(21.9 \pm 6.6 \mathrm{nM})$, and BMP-7 $(22.6 \pm 1.1 \mathrm{nM})$ to ALK5. Although ALK5 was considered to be mainly a TGF $\beta$, our data show that several BMPs can bind to ALK5, which highlights its possible role in the BMP signaling pathway. Indeed, previous data in our team show an expression of ALK5 in BMP-responsive cells notably C2C12 skeletal muscle cells and human periosteum derived stem cells. ${ }^{64}$ Moreover, it is reported that ALK5 interacts with ALK1 and inhibits BMP signaling mediated by ALK1 in the growth plate of cartilage. ${ }^{65}$ Also, BMP-2 appeared to induce complex formation between ALK3 and ALK5 in cancer cells. ${ }^{47}$ Last but not least, it was shown that different signaling through ALK1 and ALK5 regulate leptin expression in bone-marrow mesenchymal stem cells. ${ }^{16}$ Further in vivo studies should aim to unravel a possible crosstalk between TGF $\beta / B M P$ pathways mediated by ALK5.

While it is simple to connect the affinity studies directly to the downstream signaling pathway, it would be inherently incorrect not to mention other parameters affecting the signaling. Notably, the temperospatial expression of BMPs and BMPRs should be considered. $^{66}$ Besides, the BMP signaling can be affected by BMP's interaction with modular proteins (i.e., Noggin, Gremlin), coreceptors such as Endoglin, which binds BMP- ${ }^{67}$ and extracellular matrix components (i.e., fibrillary proteins and proteoglycans). ${ }^{68}$ Nevertheless, our study provides an insight into the first step of the BMP signaling.

The use of a 2:1 heterogeneous ligand model to analyze the ternary complex interactions did not yield any improvement in the binding affinity compared to the bimolecular BMP/BMPR interactions, although such a mechanism of cooperativity has been proposed. It was reported that BMP-7 affinity to ALK2 increases in 
the presence of ACTR-IIA. ${ }^{31,69}$ Nonetheless, our data do not show any cooperativity between both types of BMPRs. This result agrees with the literature since a previous SPR study of BMP-7/ALK3/ ACTR-IIA using a BMPR mix similarly reported the limitations of the system in observing a cooperativity.

\section{SUMMARY AND CONCLUSIONS}

Our study highlighted the specific differences in BMP/BMPR binding affinities. The results are consistent with the interactions previously reported; nevertheless, with our setup, we overcame the previously mentioned limitations of studying this BMP/BMPR interaction, by using a similar binding strategy. The findings help us gain insight into the signaling pathways and will guide future BMP signaling studies, with respect to BMP/TGF $\beta$ crosstalk and to the type of signaling pathway (SMAD versus non-SMAD) in addition to the specificities of the receptor (type I versus type II). It would also be interesting to further investigate in vivo the functional significance of these interactions.

\section{NOMENCLATURE}

$\begin{array}{ll}\text { ALK1 } & =\text { activin receptor-like kinase } 1 \\ \text { ALK2 } & =\text { activin receptor-like kinase } 2 \\ \text { ALK3 } & =\text { activin receptor-like kinase } 3 \\ \text { ALK5 } & =\text { activin receptor-like kinase } 5 \\ \text { ALK6 } & =\text { activin receptor-like kinase } 6 \\ \text { AMHR-II } & =\text { anti-Müllerian hormone receptor II } \\ \text { BLI } & =\text { biolayer interferometry } \\ \text { BMP-2 } & =\text { bone morphogenetic protein } 2 \\ \text { BMP-4 } & =\text { bone morphogenetic protein } 4 \\ \text { BMP-7 } & =\text { bone morphogenetic protein } 7 \\ \text { BMP-9 } & =\text { bone morphogenetic protein } 9 \\ \text { BMPR } & =\text { bone morphogenetic protein receptor } \\ \text { ECD } & =\text { extracellular domain } \\ \text { SPR } & =\text { surface plasmon resonance } \\ \text { TGF } 3 & =\text { transforming growth factor } \\ \text { TGF } \beta R & =\text { transforming growth factor receptor }\end{array}$

\section{ACKNOWLEDGMENTS}

The authors acknowledge Anne Chouquet from the ISBG platform for her help and Marianne Weidenhaupt (INPG) for discussions regarding the immobilization protocol. They are grateful to Sabine Bailly and Corinne Albiges-Rizo for fruitful discussions and advice. The study was supported by the Agence Nationale de la Recherche (ANR CODECIDE, ANR-17-CE13-022) to C.P., the European Research Council under FP7 programm (ERC Biomim GA259370) and by the Fondation Recherche Medicale (FRM, grant DEQ20170336746) to C.P. V.K. was supported by a Ph.D. fellowship from Grenoble Institute of Technology. This work used the platforms from Grenoble Instruct-ERIC Center (ISBG: UMS 3518 CNRS-CEAUGA-EMBL), within the Grenoble Partnership for Structural Biology (PSB), supported by FRISBI (No. ANR-10-INBS-05-02) and GRAL, financed within the University Grenoble Alpes graduate school (Ecoles Universitaires de Recherche) CBH-EUR-GS (No. ANR-17-EURE-0003).

\section{DATA AVAILABILITY}

The data that support the findings of this study are available from the corresponding author upon request.

\section{REFERENCES}

${ }^{1}$ C. Sieber, J. Kopf, C. Hiepen, and P. Knaus, Cytokine Growth Factor Rev. 20, 343 (2009).

${ }^{2}$ R. N. Wang et al., Genes Dis. 1, 87 (2014).

${ }^{3}$ S. Ehata, Y. Yokoyama, K. Takahashi, and K. Miyazono, Pathol. Int. 63, 287 (2013).

${ }^{4}$ S. Kishigami and Y. Mishina, Cytokine Growth Factor Rev. 16, 265 (2005).

${ }^{5}$ K. Miyazono, Y. Kamiya, and M. Morikawa, J. Biochem. 147, 35 (2010).

${ }^{6}$ T. D. Mueller and J. Nickel, FEBS Lett. 586, 1846 (2012).

${ }^{7}$ M. R. Urist, Science 150, 893 (1965).

${ }^{8}$ V. E. Santo, M. E. Gomes, J. F. Mano, and R. L. Reis, Tissue Eng., Part B 19, 308 (2013)

${ }^{9} \mathrm{C}$. Busch and H. Wheadon, Biochem. Soc. Trans. 47, 1307 (2019).

${ }^{10}$ L. Grgurevic, G. L. Christensen, T. J. Schulz, and S. Vukicevic, Cytokine Growth Factor Rev. 27, 105 (2016).

${ }^{11}$ Nicholas W. Morrell, Donald B. Bloch, Peter ten Dijke, Marie-Jose T. H. Goumans, Akiko Hata, Jim Smith, Paul B. Yu, and Kenneth D. Bloch, Nat. Rev. Cardiol. 13, 106 (2016).

${ }^{12}$ P. Jiramongkolchai, P. Owens, and C. C. Hong, Biochem. Soc. Trans. 44, 1117 (2016).

${ }^{13}$ K. Miyazono, K. Kusanagi, and H. Inoue, J. Cell. Physiol. 187, 265 (2001).

${ }^{14}$ D. Carvalho et al., Commun. Biol. 2, 156 (2019).

${ }^{15}$ F. Zylbersztejn, M. Flores-Violante, T. Voeltzel, F. E. Nicolini, S. Lefort, and V. Maguer-Satta, Exp. Hematol. 61, 36 (2018).

${ }^{16}$ M. Zeddou, B. Relic, O. Malaise, E. Charlier, A. Desoroux, Y. Beguin, D. De Seny, and M. G. Malaise, Stem Cells Dev. 21, 1948 (2012).

${ }^{17}$ C. Hiepen et al., PLoS Biol. 17, e3000557 (2019).

${ }^{18}$ J. W. Lowery and V. Rosen, Physiol. Rev. 98, 2431 (2018).

${ }^{19}$ D. Yadin, P. Knaus, and T. D. Mueller, Cytokine Growth Factor Rev. 27, 13 (2016).

${ }^{20}$ G. Sanchez-Duffhues, E. Williams, M. J. Goumans, C. H. Heldin, and P. ten Dijke, Bone 138, 115472 (2020).

${ }^{21}$ J. Nickel and T. D. Mueller, Cells 8, 1579 (2019).

${ }^{22}$ S. Aykul and E. Martinez-hackert, J. Biol. Chem. 291, 10792 (2016).

${ }^{23}$ T. Kirsch, J. Nickel, and W. Sebald, EMBO J. 19, 3314 (2000).

${ }^{24}$ W. Sebald, J. Nickel, J. L. Zhang, and T. Mueller, Biol. Chem. 385, 697 (2004).

${ }^{25}$ G. P. Allendorph, M. J. Isaacs, Y. Kawakami, J. C. I. Belmonte, and S. Choe, Biochemistry 46, 12238 (2007).

${ }^{\mathbf{2 6}}$ A. Kotzsch et al., J. Biol. Chem. 283, 5876 (2008).

${ }^{27}$ K. Heinecke, A. Seher, W. Schmitz, T. D. Mueller, W. Sebald, and J. Nickel, BMC Biol. 7, 59 (2009).

${ }^{28}$ K. Yamawaki, Y. Kondo, T. Okada, T. Oshima, M. Kakitani, and K. Tomizuka, Sci. Rep. 6, 3 (2016).

${ }^{29}$ H. J. Seeherman et al., Sci. Transl. Med. 11, 1 (2019).

${ }^{30}$ G. P. Allendorph, W. W. Vale, and S. Choe, Proc. Natl. Acad. Sci. U.S.A. 103, 7643 (2006).

${ }^{31}$ J. Greenwald, J. Groppe, P. Gray, E. Wiater, W. Kwiatkowski, W. Vale, and S. Choe, Mol. Cell 11, 605 (2003).

${ }^{32}$ P. Mahlawat, U. Ilangovan, T. Biswas, L. Z. Sun, and A. P. Hinck, Biochemistry 51, 6328 (2012).

${ }^{33}$ S. Saremba, J. Nickel, A. Seher, A. Kotzsch, W. Sebald, and T. D. Mueller, FEBS J. 275, 172 (2008)

${ }^{34}$ T. Hatta, H. Konishi, E. Katoh, T. Natsume, N. Ueno, Y. Kobayashi, and T. Yamazaki, Biopolymers 55, 399 (2000).

${ }^{35}$ G. Szláma, K. Kondás, M. Trexler, and L. Patthy, FEBS J. 277, 5040 (2010).

${ }^{36}$ S. A. Townson et al., J. Biol. Chem. 287, 27313 (2012).

${ }^{37}$ Y. Kienast et al., J. Biol. Chem. 291, 3395 (2016). 
${ }^{38}$ R. M. Salmon et al., Nat. Commun. 11, 1 (2020).

${ }^{39}$ D. Mitchell et al., Mol. Cancer Ther. 9, 379 (2010).

${ }^{40}$ C. Hänel and G. Gauglitz, Anal. Bioanal. Chem. 372, 91 (2002).

${ }^{41}$ G. Gauglitz, Anal. Bioanal. Chem. 412, 3317 (2020).

${ }^{42}$ Y. Abdiche, D. Malashock, A. Pinkerton, and J. Pons, Anal. Biochem. 377, 209 (2008).

${ }^{43}$ A. Sultana and J. E. Lee, Curr. Protoc. Protein Sci. 79, 19251 (2015).

${ }^{44}$ D. Frenzel and D. Willbold, PLoS One 9, e106882 (2014).

${ }^{45}$ D. O. Wagner, C. Sieber, R. Bhushan, J. H. Börgermann, D. Graf, and P. Knaus, Sci. Signal 3, mrl (2010).

${ }^{46}$ J. Massagué, Annu. Rev. Biochem. 67, 753 (1998).

${ }^{47}$ A. Holtzhausen, C. Golzio, T. How, Y. H. Lee, W. P. Schiemann, N. Katsanis, and G. C. Blobe, FASEB J. 28, 1248 (2014).

${ }^{48}$ G. Blin, E. Margeat, K. Carvalho, C. A. Royer, C. Roy, and C. Picart, Biophys. J. 94, 1021 (2008).

${ }^{49}$ M. J. Isaacs, Y. Kawakami, G. P. Allendorph, B. H. Yoon, J. C. Izpisua Belmonte, and S. Choe, Mol. Endocrinol. 24, 1469 (2010).

${ }^{50}$ D. Weber, A. Kotzsch, J. Nickel, S. Harth, A. Seher, U. Mueller, W. Sebald, and T. D. Mueller, BMC Struct. Biol. 7, 6 (2007).

${ }^{\mathbf{5 1}}$ M. Ehrlich, O. Gutman, P. Knaus, and Y. I. Henis, FEBS Lett. 586, 1885 (2012).

${ }^{52}$ L. Traeger et al., Free Radic. Biol. Med. 129, 127 (2019).

${ }^{53}$ J. C. Perron and J. Dodd, PLoS One 4, e8198 (2009).

${ }^{54}$ B. Shu et al., J. Cell Sci. 124, 3428 (2011)

${ }^{55}$ T. Voeltzel et al., Cell Death Dis. 9, 1011 (2018).

${ }^{56}$ S. Lefort and V. Maguer-Satta, Biochem. Soc. Trans. 48, 411 (2020).

${ }^{57}$ F. S. Kaplan, P. Seemann, J. Haupt, M. Xu, V. Y. Lounev, M. Mullins, and E. M. Shore, Methods Enzymol. 484, 357 (2010).

${ }^{58}$ K. Lavery, P. Swain, D. Falb, and M. H. Alaoui-Ismaili, J. Biol. Chem. 283, 20948 (2008).
${ }^{59}$ M. Scharpfenecker, M. van Dinther, Z. Liu, R. L. van Bezooijen, Q. Zhao, L. Pukac, C. W. G. M. Löwik, and P. ten Dijke, J. Cell Sci. 120, 964 (2007).

${ }^{60}$ L. David, C. Mallet, S. Mazerbourg, J. J. Feige, and S. Bailly, Blood 109, 1953 (2007).

${ }^{61}$ B. N. Ray, N. Y. Lee, T. How, and G. C. Blobe, Carcinogenesis 31, 435 (2010).

${ }^{62}$ J. Luo et al., J. Biol. Chem. 285, 29588 (2010).

${ }^{63}$ M. A. Brown et al., J. Biol. Chem. 280, 25111 (2005).

${ }^{64}$ A. Sales, V. Khodr, P. Machillot, L. Fourel, A. Guevara-Garcia, E. Migliorini, C. Albigès-Rizo, and C. Picart, Biorxiv (2021).

${ }^{65}$ W. Wang, H. Chun, J. Baek, J. E. Sadik, A. Shirazyan, P. Razavi, N. Lopez, and K. M. Lyons, Proc. Natl. Acad. Sci. U.S.A. 116, 15570 (2019).

${ }^{66} \mathrm{~K}$. Miyazono, S. Maeda, and T. Imamura, Cytokine Growth Factor Rev. 16, 251 (2005).

${ }^{67}$ D. P. Brazil, R. H. Church, S. Surae, C. Godson, and F. Martin, Trends Cell Biol. 25, 249 (2015).

${ }^{68}$ E. Migliorini, A. Guevara-Garcia, C. Albiges-Rizo, and C. Picart, Bone 141, 115540 (2020).

${ }^{69}$ W. Sebald and T. D. Mueller, Trends Biochem. Sci. 28, 518 (2003).

${ }^{\mathbf{7 0}}$ See supplementary material at https://www.scitation.org/doi/suppl/10.1116/ 6.0000926 for S1 TABLE 1. Detailed literature study table summarizing the KD (nM) of the BMP/type-I and type-II BMPR interaction couples; S2 FIGURE 1. Image of a gel electrophoresis showing all the used BMPs, ALKs and type-II BMPR; S3 TABLE 2. Detailed kinetic tables indicating the KD (nM), ka (M-1.s$1), \mathrm{kd}(\mathrm{s}-1)$ and R2 of the BMP/type-I interaction couples; S4 TABLE 3. Detailed kinetic tables indicating the $\mathrm{KD}$ (nM), ka (M-1.s-1), kd (s-1) and $\mathrm{R} 2$ of the BMP/type-II interaction couples; S5 FIGURE 2. Binding kinetics between nonglycosylated and glycosylated BMP-4 with ALK3; S6 FIGURE 3. SPR binding curve for BMP-2/ALK3; S7 FIGURE 4. BLI binding kinetics of BMP-2 with ALK2 and ACTR-IIB in two confirmations using 1:1 fit. 